\title{
A RE-PAINTED AMAZON
}

Graeme Earl ${ }^{1}$, Gareth Beale ${ }^{1}$, Jassim Happa ${ }^{2}$, Mark Williams ${ }^{3}$, Glen Turley ${ }^{3}$, Kirk Martinez ${ }^{4}$ and Alan Chalmers ${ }^{2}$

1 Archaeological Computing Research Group

School of Humanities

University of Southampton

Southampton

UK

graeme.earl@soton.ac.uk

http://www.southampton.ac.uk/archaeology/acrg/

2 The Digital Laboratory, University of Warwick, UK

3 Warwick Manufacturing Group, University of Warwick, UK

4 Electronics and Computer Science, University of Southampton, UK

Abstract - This paper describes an ongoing project to digitally record, reconstruct and repaint a 2000-year-old painted Roman statue from Herculaneum, Italy. The paper considers the archaeological potential for extremely detailed laser scanning and digital recreation of Roman statuary, and visualisation within a physically accurate context. It focuses on the archaeological significance of the emerging technologies employed and their potential to illuminate our understanding of concepts such as Roman aesthetics and the impact of spatial context on perception of statues.

\section{INTRODUCTION}

The head of a Roman marble statue, dating to between the first century BC and the eruption of Vesuvius in AD79, was discovered during conservation works at the site of Herculaneum in Italy in 2006 (figure 1) [1,2]. It was found in the area of what has been interpreted as the Basilica Noniana in the NE corner of the excavated area. Pigments on the statue in shades of red and brown are exceptionally well-preserved, providing a delicate augmentation of the natural and sculpted relief of the white Pentelic marble surface. Painting picks out details such as eyelashes, hair and facets of the eyes. Although sculptural artefacts from Herculaneum with traces of polychromy are numerous the state of preservation of the pigment made this an exceptional find. The Roman sculptural corpus is dominated by beautiful, pristine marble examples but the original appearance of the statues - painted, and perhaps ornamented and draped remains little known and has been a consistent subject of debate.

The Herculaneum head was probably carved in the late first century BC or early first century AD. It has been interpreted as being from a full size statue of a 'wounded Amazon', a type of Roman statue commonly seen as a copy of Classical Greek bronze originals of the fifth century $\mathrm{BC}$ [3]. It was discovered during work undertaken by the Herculaneum Conservation Project (HCP) which has in recent years been engaged in a 


\section{EVA 2009 London Conference 6-8 July \\ Graeme Earl et al.}

vital programme of consolidation and recording at Herculaneum. Initial expert analysis of the head identified it as of a particular type of Amazon known as the Sciarra. The sculpture is not alone at Herculaneum in exhibiting considerable traces of polychromy. In fact a head of the same type was found in excavations nearby at the Villa of the Papyri in 1997.
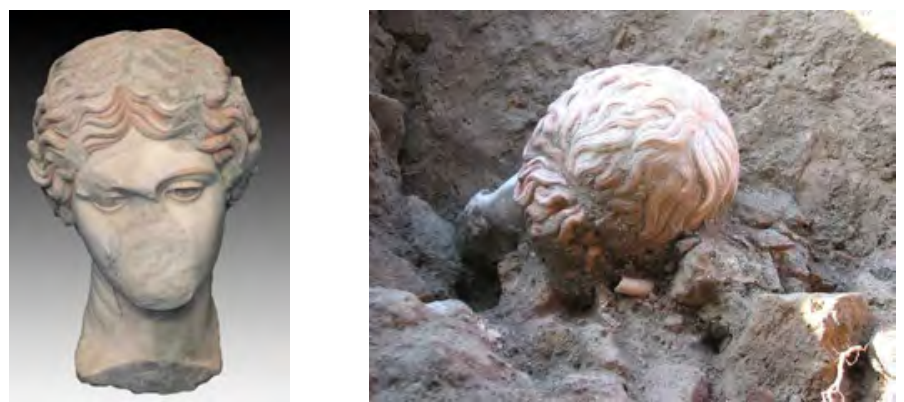

Figure 1. The Amazon Head (Paola Pesaresi/ Herculaneum Conservation Project, with the kind permission of the Soprintendenza Speciale per i Beni Archeologici di Napoli e Pompeii)

The Basilica Noniana lies on the edge of the public part of the Roman town which still lies buried beneath modern Ercolano. Previous interventions in this area have been limited to exploratory tunnels dug down through $20 \mathrm{~m}$ of volcanic deposit during the 18th and 19th centuries. The body of the Amazon is presumed to lie within this as yet unexcavated portion of the Basilica. Other work involving the University of Southampton on the site may add to our knowledge of this and other areas, with a team recently having visited the site to conduct a Ground Penetrating Radar geophysical survey (GPR). This enables a thee-dimensional view of the buried building to be modelled without excavation, and complements work by $\mathrm{HCP}$ on site recording the tunnels and exposed architectural features.

The work described in this paper focussed on the digital recording, reconstruction and repainting of the statue, and in particular on the possibilities afforded for interpretation by these approaches. It has begun to consider how the polychrome nature of Roman statuary might be better understood through the study of its perception within a digitally simulated spatial context. The possibilities afforded by computer graphics and laser scanning for archaeological and art historical interpretation, enhanced by partnerships between industry, archaeology and the cutting-edge of computer graphics, are considerable. Potential uses of the technology include:

1. Provision of a detailed and accessible conservation record

2. Spatial and contextual interpretation through lighting

3. Stylistic analysis.

From a computer graphics perspective the challenges of ultra-realistic representation of high surface complexity models, in combination with complex marble and paint surface interactions, are considerable. 


\section{ANALYSING STATUES IN CONTEXT}

This project is focussed on how the polychrome nature of Roman statuary can be better understood through the study of its perception within a digitally simulated spatial context. It is our contention that virtual reconstruction, repainting and recontextualisation together provide a unique opportunity to consider the statue within visually coherent, highly accurate and extremely adaptable Roman spaces. Until now such an appraisal of painted statues in context has been restricted to imagination, or to the possibilities of physical repainting and reconstruction [4,5] which tend to be both inflexible and expensive.

The fact that in our approach both the context and the statue are wholly virtual does not limit interpretation to simple assessments of form and impression. We believe that not only should digital reconstruction require careful documentation but interpretations derived from its resulting imagery should be related to visual experience in the physical world. Elsewhere [6] we have considered the value of digital perception per se but in this context we stress the value of perceptual authenticity. Modern engineering brings the opportunity not merely to produce a view that appears real (so called 'photorealistic rendering') but is also demonstrably real. Indeed the recently increased requirement for, and possibilities of, exact visual replication imposed on contemporary graphics work by sectors such as medical simulation, architectural lighting design, the military and other 'serious games' [7] industries means that the interpretative input available is an order of magnitude greater than that previously encountered. In other words the patterns of colour, light and shade are created using abstractions from the same physical laws that govern a real scene. Such visual fidelity will in a short time be accompanied by fully immersive, multi-sensory environments which are also quantifiably related to realworld experience [8].

\section{Potential for Digital Visual Interpretation}

The application of computer graphics approaches within archaeology has a long history and is now relatively uncontroversial. Representational theory has considered archaeological computer graphics in detail, moving research forward from what was in the past at times a rather naive application of method to topic. Researchers are now in an excellent position, since not only do the aims and approaches of archaeologists and computer scientists complement one another and have a shared language, but the technology is finally starting to live up to previous hyperbole. Indeed, one may argue that any consideration of space and vision in archaeological research is impoverished without consideration of three-dimensional computation. Similarly, it is no longer acceptable to define computation and theory as distinct components to archaeological practice [9].

Engaging with complex spatial factors influencing the perception of Roman statues in context, such as the effects of interior lighting and ambient colour, has been extremely difficult. However, research from art history has considered issues such as proposed orientation, posture, and context in relation to viewer position [10]. The Herculaneum Amazon head research extends such work by proposing that in order to develop further visual analyses of Roman statuary one must move beyond an object- 
centred typological approach, and instead attempt to place statues in hypothesised 'original' spatial contexts [11,12]. Through these means it is possible to develop meaningful hypotheses regarding the ways in which built spaces informed the visual nature of statuary, and also the ways in which the visual structure, physical restrictions, orientation and appearance of these spaces can be accounted for by the planned presence of statuary. These approaches signify a considerable step towards the development of meaningful understandings of Roman statuary within architectural context. In particular the computer offers the potential for infinite variation in aspects such as pigment application, or location and orientation of the statue, or even of the lighting which is likely to have been critical to the statue's original appreciation.

In particular it is hoped that the possibilities for relighting using both natural light and artificial illumination such as oil lamps will assist in interpretation [13]. Current analyses of sculptural composition have much to do with viewing angle, and computer graphic simulation provides for limitless modifications to this orientation of viewer and object, and also to patterns of light and shade. For example, analyses based on the relative detail with which parts of a sculpture are rendered in stone do not always account for the interplay of lighting across their surface. But work has suggested that particular intended viewing angles influence sculptural detail, without considering variations in lighting. Clearly lighting will determine to a great degree the focus of attention and perception of depth, scale and colour and yet the modern representational context of Classical statuary does not easily allow for these kinds of interpretation to be developed. In part this is because lighting is a function of locations and material components of a given scene that exist nowhere today, even in the extraordinary context of Herculaneum. Furthermore, even where such environments survive in fragmentary form the impact on perception afforded by factors such as dust, smoke and other participating media can rarely be examined due to the fragility and value of ancient artefacts [14]. One cannot simply place a lighted oil lamp against a Roman wall.

\section{Sculptural Polychromy}

The importance of polychromy to our understanding of Roman sculpture and of Roman attitudes toward colour more broadly cannot be underestimated. Polychromy was a feature of Roman sculpture of all periods. The area around Vesuvius provides a rich corpus of painted Roman statuary, supplemented by other finds from around the Roman Empire. Extant coloured examples from Herculaneum include the Sciarra Amazon, a portrait of the Empress Agrippina, and the Amazon from the Villa of the Papyri. Examples of polychromy are also present in the Pompeiian collections in Naples, including the Venus from the House of Iulia Felix, the Venus Lovatelli, and the statue of Livia from Villa of the Mysteries. Surviving examples demonstrate polychromy in use in both domestic and civil settings. Painted sculptures were of varying standard from the very highest quality of imperial portrait to items of domestic decoration [15]. Work in art history and archaeology has demonstrated the importance of seeing and understanding statuary in context [16]. Surviving polychromy is described by a number of authors [17]. In order to develop meaningful and truly insightful notions of Roman use of colour and the visual nature of domestic and civil space it is essential 


\section{EVA 2009 London Conference 6-8 July \\ Graeme Earl et al.}

that this subject receives more critical attention and the application of all analytical resources available. However, quality of extant data and concomitant analyses of polychromy in Roman statuary are limited. The wider issues of its postulated ubiquity, and its relevance to design and consumption, remain as a consequence under-theorised.

There has been no previous attempt to use the technology described here to aid in such analyses. The possibilities that digital representations offer to provide a surrogate visual experience are considered in depth by a number of authors [18], but never in the context of polychrome statuary. The formative studies lack the physical basis now possible [19] whilst those important studies that have taken place more recently make use of advanced analyses but are focussed on physical rather than virtual reconstruction [20]. However, such comprehensive physical studies are essential to the understanding of Roman pigment composition and use, and are in turn a vital element in analysis of their appearance, whether virtual or real, in context. Unfortunately where digital representations of statuary are produced they do not generally employ physically accurate rendering technologies. Commonly the visual output, although attractive, has only little basis in fact. Indeed, with exceptions [21], the abstract quality of visuals still predominates in the visualisation of Roman material culture and architecture.

\section{DIGITAL RECORDING}

Accuracy and accountability are necessary prerequisites for the creation of meaningful interpretations which rely upon colour, light and space. In order for hypotheses based upon the reconstruction of these variables to be sound it is necessary that all recorded data is extremely accurate and that all decisions made during the process of reconstruction are accountable and justified.

\section{Accurate recording of surface geometry}

A Metris laser scanner (figure 2) was used to capture the geometry of the statue at Herculaneum. The laser scanner provided a highly accurate point and surface representation of the surface being scanned without having to make any physical contact, a necessity when dealing with surfaces as fragile as those in question. The equipment is capable of recording 80,000 points per second at a resolution of between $0.05 \mathrm{~mm}$ and $0.06 \mathrm{~mm}$, producing extremely fine, accurate records of any object's surface. 


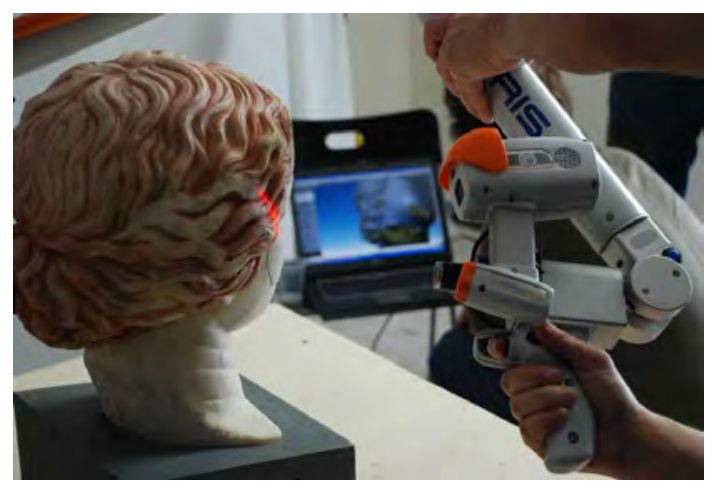

Figure 2. Scanning using a Metris Coordinate Measuring Arm (Hembo Pagi/ ACRG)

\section{Accurate recording of calibrated colour data}

Various techniques were employed to ensure the provision of an objective record of the surviving surface colour of the statue, both in terms of pigment and the properties of the marble. Colour capture of the statue included collection of high dynamic range imaging (HDRI) and colorimetry, using a PR680 spectrophotometer [22]. These will provide additional input to renders and enable comparison of recorded and simulated surfaces. Polynomial Texture Mapping (PTM) was also employed to capture fine surface colour details (figure 3). This technique enables physically defined surface properties related to angle of view to be recorded. The technology was invented by Hewlett-Packard Labs [23] and provides a detailed model of the surface reflectance properties of the object recorded, and its texture. The Tate used the technique in an exhibition of Frank Auerbach's Variable Light, and there have been other applications in art including work by the National Gallery [24], on numismatic data [25], and to supplement computer graphics work on Byzantine mosaics [26]. A recording system was developed at Southampton in the Archaeological Computing Research Group and the School of Electronics and Computer Science that enabled very rapid and accurate recording of PTMs. The resulting Amazon PTM datasets (figure 4) were used as a calibration for digital renders, and in order to enhance the surface geometry datasets captured via the scanner.
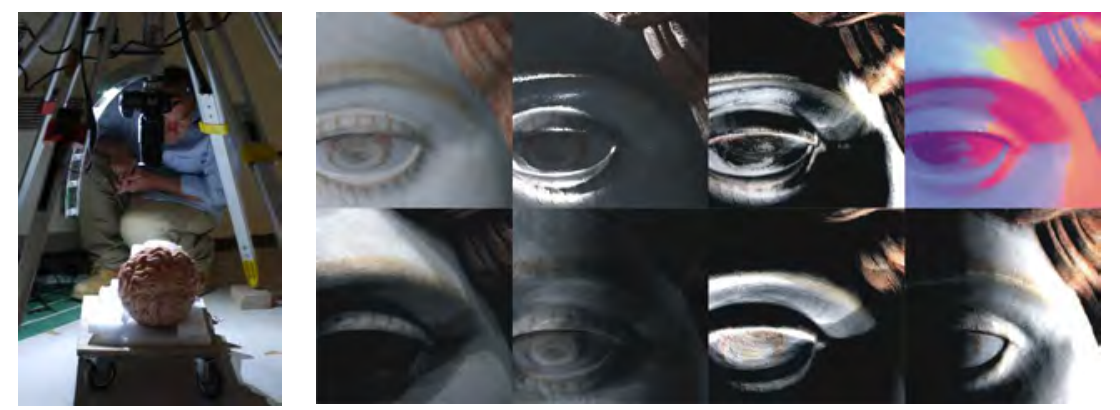

Figures 3 and 4. The PTM rig (Hembo Pagi/ ACRG); PTM dataset derived from the Amazon, illustrating surface reflectance properties with lighting in alternate locations, with specular and diffuse enhancement, and with extracted surface normals 


\section{Virtual Reconstruction and Repainting}

The advanced computer science and engineering methodologies employed by the project team provide archaeologists with an infinitely variable, otherwise impossible view of how the original statue may have looked in context, and allow experimentation with alternative hypotheses. The face has a large portion missing, primarily the nose, mouth and a portion of the cheek. The reconstruction through amalgamation of many differently shaped, oriented and styled scanned exemplars may prove an important part in the interpretation of the statue. This will augment the considerable value of the approach as a mechanism for sharing ideas, for relighting and contextual interpretation, and for presenting final alternatives to a wider public. We have begun to reconstruct the face based on data gathered from laser scans of casts of comparable statue types. Initial computer graphic renders have also been produced that enable us to gauge the extent to which the simulation is able to replicate reality (figures 5 and 6).

The visual analysis of the Amazon is based on the unique potential of computer modelling to produce multiple versions. Hypothesised alternatives of the painted statues are being modelled, in the first place, to consider the influence of orientation on their sculpted form, composition and visual impact. Secondly, differences in form and pose are being examined in relation to surface painting, variations in surface detailing, and architectural context. Variations in simulated lighting will determine to a great degree the focus of attention and the perception of depth, scale and colour. Reconstructed lighting models can be entirely different to those which might exist or be created within a museum context. The preservation at Herculaneum also means that a likely original context for the statue is relatively well understood and can therefore be recreated.
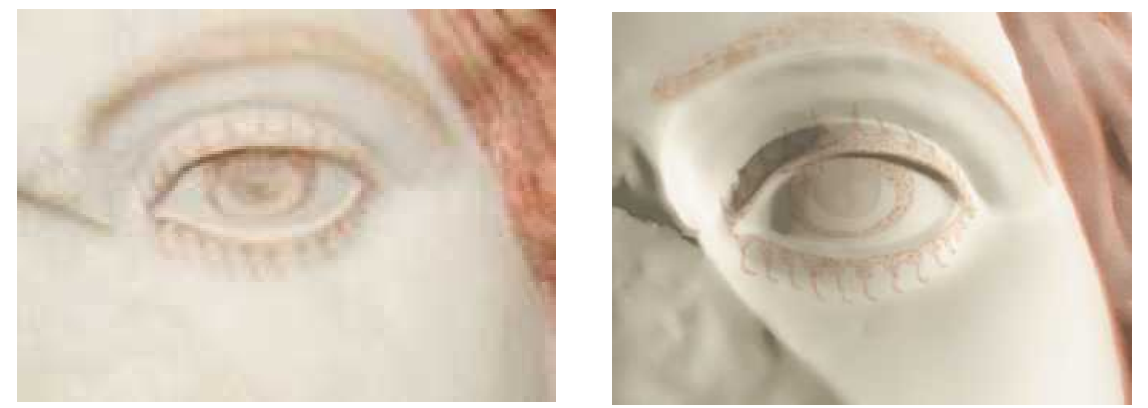

Figures 5 and 6. The Amazon Statue photographed (Paola Pesaresi/ HCP) and with an initial render which makes no use of photographic textures

To date we have produced an initial Roman architectural test environment within which to visualise the digitally painted statue (figure 7) 


\section{EVA 2009 London Conference 6-8 July \\ Graeme Earl et al.}

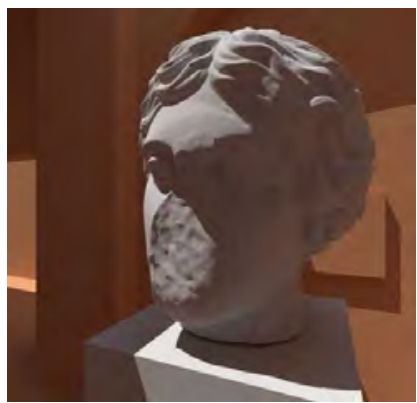

Figure 7. Contextual visualisation using physically based renderer

\section{CONCLUSIONS AND FURTHER WORK}

The potentials of the computer graphic modelling, relighting and rendering of the statue are only just being appreciated but the case study has defined a series of additional research areas for further attentions. We hope in time to apply additional nondestructive tomographic techniques to the statue. This will enable the recording and subsequent simulation of its sub-surface. This is a vital component in the distribution of light and colour on marble surfaces, and equally on the human skin that they mimic. Such 'sub-surface scattering' details are one of many components of the technologies proposed that differentiate a visually appealing from a visually accurate rendering. Future visualisation work will also benefit from emerging research in Bidirectional Reflectance Distribution Function (BRDF) rendering, and in particular work on Bidirectional Texture Functions. These techniques will enable an even greater level of physical accuracy in representation.

\section{ACKNOWLEDGEMENTS}

The Soprintendenza Speciale per i Beni Archeologici di Napoli e Pompei generously provided access to the statue and its staff were of very great assistance throughout the complex recording process. The work would also have been impossible without the support and knowledge of members of the Herculaneum Conservation Project and in particular its director Andrew Wallace-Hadrill and its research coordinator Sarah Court. The Herculaneum Conservation Project is a partnership between the Packard Humanities Institute, Soprintendenza Speciale per $i$ Beni Archeologici di Napoli e Pompei and the British School at Rome.

\section{References}

[1] HAPPA, J., WILLIAMS, M., TURLEY, G., EARL, G., DUBLA, P., BEALE, G., GIBBONS, G., DEBATTISTA, K. and CHALMERS, A. Virtual relighting of a Roman statue head from Herculaneum, a case study. In : Proceedings of Afrigraph 2009, Pretoria, South Africa, February 4-6, 2009. ACM, 2009. pp.512.

[2] GUIDOBALDI, M. P. Una testa di amazzone dipinta. Forma Urbis. 11.4, pp.47.

[3] RIDGWAY, B. S. A story of five amazons. American Journal of Archaeology, 78. pp1-17. 
EVA 2009 London Conference 6-8 July

Graeme Earl et al.

[4] WÜNSCHE, R. Il colore ritorna. In : Liverani, P (ed) I colori del bianco : policromia nella scultura antica. De Luca, 2004. pp 13-28.

[5] HUET, V. Stories one might tell of Roman art. In : Elsner, E. (ed) Art and text in Roman culture. Cambridge University Press, 1996. pp.10-31.

[6] CRIPPS, P.J., EARL, G.P. and WHEATLEY, D.W. A dwelling place in bits. Journal of Iberian Archaeology, 8, 2006.

[7] CHALMERS, A. and DEBATTISTA, K. Levels of realism for serious games. IEEE VS-Games'09 : First International IEEE Conference in Serious Games and Virtual Worlds. IEEE Press, 2009.

[8] CHALMERS, A., HOWARD, D. and MOIR, C. Real virtuality : a step change from virtual reality. In : SCCG'09 : Spring Conference on Computer Graphics. ACM SIGGRAPH Press, 2009. pp.15-22.

[9] EARL, G.P. De/construction sites : Romans and the digital playground. In : Bowen, J., Keene, S. and MacDonald, L. (eds) EVA 2007 London Conference Proceedings. Hampton Hill, UK, EVA Conferences International, 2007.

[10] STURGEON, M. The Corinth Amazon : formation of a Roman classical sculpture. American Journal of Archaeology, 99, 1995. pp. 483-505.

[11] ELSNER, J. Art and the Roman viewer. Cambridge University Press, 1995.

[12] BARTMAN, E. 1994. Sculptural collecting and display in the private realm. In: Gazda, E. K. (ed.) Roman art in the private sphere. University of Michigan Press, 1994. pp.72-73.

[13] GONAlVES A., MAGAlHES, L., MOURA, J. and CHALMERS, A. Accurate modelling of Roman lamps in Conimbriga using high dynamic range. In : : Proceedings of VAST 2008 : 9th International Symposium on Virtual Reality, Archaeology and Cultural Heritage. Eurographics, 2008.

[14] SUNDSTEDT, V., GUTIERREZ, D., ANSON, O., BANTERLE, F. and CHALMERS, A. Perceptual rendering of participating media. In : $A C M$ Transactions on Applied Perception, 4(3). New York : ACM Press, 2007. pp 15.

[15] ØSTERGAARD, J.S. Emerging colors : Roman sculptural polychromy revived. In : Panzanelli, R. (ed.) The color of life : polychromy in sculpture from antiquity to the present. [Exhibition catalogue] Malibu : J. Paul Getty Museum, 2008. pp.40-61.

[16] CLARKE, J. R. The houses of Roman Italy 100 B.C. - A.D. 250 : ritual space and decoration. University of California Press, 1991.

[17] BEARD, M. and HENDERSON, J. Classical art from Greece to Rome. Oxford University Press, 2001.

[18] GILLINGS, M. The real, the virtually real and the hyperreal : the role of VR in archaeology. In : Smiles, S. and Moser, S. (eds.) Envisioning the past. Blackwell, 2005. pp 223-239.

[19] REUTERSWÄRD, P. Studien zur Polychromie der Plastik. Griechenland und Rom. Stockholm, 1960.

[20] BRINKMANN, V. Colori e tecnica pittorica. liverani, P (ed.) In : I colori del bianco : policromia nella scultura antica. De Luca, 2004. pp.315-324. 
[21] HASELBERGER, L. and HUMPHREY, J. (eds) Imaging Ancient Rome. Journal of Roman Archaeology Supplementary Series 61. 2006.

[22] PR-680 SpectraDuo Spectroradiometer/Photometer details. Available from: http://www.photoresearch.com/current/pr680.asp [Last accessed 27 May 2009]

[23] MALZBENDER, T., GELB, D. and WOLTERS, H. Polynomial texture maps. In : SIGGRAPH '01 : Proceedings of the 28th annual conference on computer graphics and interactive techniques. New York, NY : ACM, 2001. pp.519-528.

[24] PADFIELD J., SAUNDERS D., MALZBENDER T. Polynomial texture mapping : a new tool for examining the surface of paintings. ICOM Committee for Conservation, 2005. pp.504-510.

[25] ZÁNYI, E., CHRYSANTHOU, Y., BASHFORD-ROGERS, T. and CHALMERS, A. High dynamic range display of authentically illuminated Byzantine Art from Cyprus. In : Proceedings 8th International Symposium on Virtual Reality, Archaeology and Cultural Heritage. VAST, 2007.

[26] MUDGE, M., VOUTAZ, J. P., SCHROER, C., and LUM, M. Reflection transformation imaging and virtual representations of coins from the hospice of the Grand St. Bernard. In : Proceedings of 6th International Symposium on Virtual Reality, Archaeology and Intelligent Cultural Heritage (VAST'05). (M. Mudge, N. Ryan, and R. Scopigno, Eds). Eurographics. pp.29-41. 